Таким образом, применение мультимедийных технологий обучения в подготовке будущего педагога в режиме дистанционного образования, должно стать средством свободного творческого саморазвития каждого будущего педагога и эффективной самоорганизации его деятельности.

$$
* * *
$$

1. Зайцев В.С. Мультимедиатехнологии в образовании: современный дискурс /В.С. Зайцев. - Челябинск: "Библиотека А. Миллера" 2018. - 30с.

2. Яковлев А.И. Информационно-коммуникативные технологии в дистанционном обучении: Доклад на круглом столе "ИКТ в дистанционном образовании". - М.: МИА, 1999. -14c.

3. Романов А.Н., Торопцов В.С., Григорович Д.Б. Технология дистанционного обучения в системе заочного экономического образования. - М.: ЮНИТИ-ДАНА., 2000. -303с.

4. Новые информационные технологии в учебном процессе Мультимедийные обучающие программы /Г.А. Кручинина Нижний Новгород, 2010

\title{
Царева Г.В. \\ Организация самостоятельной работы студентов технического вуза по гуманитарным предметам с применением тестового контроля
}

Брянский государственный технический университет

(Россия, Брянск)

doi: 10.18411/trnio-09-2021-63

\section{Аннотация}

Статья посвящена вопросам организации самостоятельной работы студентов по гуманитарным предметам в техническом вузе. Особое внимание уделено осуществлению контроля за самостоятельной работой студентов посредством тестирования. Так же рассматривается применение тестов на различных этапах педагогического контроля.

Ключевые слова: самостоятельная работа студентов, тестирование, педагогический контроль, процесс обучения, гуманитарные предметы, дистанционное обучение.

\section{Abstract}

The paper is devoted to the problem of organization of students' independent work in humanities at a technical university. Special attention is paid to monitoring the independent work of students through testing. The application of tests at various stages of pedagogical control is also considered.

Keywords: students' independent work, testing, pedagogical control, training process, humanities, distance learning.

Самостоятельная работа студентов является важной составляющей процесса обучения. Это относится как к специальным дисциплинам, так и к циклу гуманитарных предметов, которые входят в обязательный блок программы обучения любого направления в рамках бакалавриата и магистратуры. Анализ рабочих программ гуманитарных дисциплин, в частности иностранного языка, показывает, что на самостоятельную работу выделяется больше часов по сравнению с аудиторными занятиями. В связи с этим эффективность организации самостоятельной работы студентов по тому или иному предмету остается актуальной и требует постоянной модернизации.

Традиционно организация самостоятельной работы студентов рассматривается как составляющая из трех элементов: планирование, методическое обеспечение, оценка и контроль. Признавая важность всех составляющих, мы обращаем свое внимание на контроль. Это обусловлено тем, что гуманитарные предметы в техническом вузе изучаются на младших курсах. А при организации самостоятельной работы на младших курсах следует принимать во внимание тот факт, что студентам первых курсов трудно совершить резкий переход от школьной методики с постоянным контролем со стороны учителя к вузовской, 
где большее значение приобретает самоконтроль. Использование тестирования является, по нашему мнению, той переходной формой, которая поможет студентам младших курсов приобрести навыки самостоятельной работы.

Педагогический контроль рассматривается как составляющая образовательной диагностики наряду с проверкой, оцениванием, анализом статистических данных, выявлением динамики образовательных изменений и личностных приращений обучаемого. Педагогический контроль определяется как система научно-обоснованной проверки результатов обучения, которая заключается в выявлении, измерении и оценивании знаний, умений, навыков и установлении разницы между реальным и запланированным уровнем освоения учебной программы $[3,5,6]$. Целью контроля является оценка качества знаний и получение информации для прогнозирования и корректировки дальнейшего развития процесса обучения.

Одним из наиболее популярных методов контроля, который используется в образовательных учреждениях разного уровня, при организации контроля по любому учебному предмету, а также применяется на всех этапах, является тестирование. Тестирование приобретает особую актуальность при применении технологий дистанционного обучения, активно использующихся в период пандемии COVID-19. Оно позволяет достаточно качественно и быстро проверить определенные знания студентов без дополнительных затрат времени на оценивание результатов тестирования.

В современном понимании дидактический тест - это инструмент, состоящий из квалиметрически выверенной системы тестовых заданий, стандартизированной процедуры проведения и заранее спроектированной технологии обработки и анализа результатов, предназначенный для измерения качеств и свойств личности, измерение которых возможно в процессе систематического обучения [4].

Показателями эффективности тестов являются его надежность и валидность.

Под надежностью теста понимается согласованность результатов теста, получаемых при повторном его применении на одной и той же группе испытуемых при разных условиях. В широком смысле надежность теста показывает, в какой степени индивидуальные различия в тестовых результатах оказываются «истинными», а в какой могут быть приписаны случайным ошибкам [3].

Валидность теста - соответствие теста тому, что он измеряет, то есть насколько хорошо он это делает. Для оценки качества тестов выделяются различные виды валидности: валидность целеполагания показывает, насколько содержание теста соответствует цели диагностирования; валидность соответствия заключается в соответствии результатов, полученных при использовании дидактических тестов и результатов, полученных при помощи других форм контроля; валидность прогноза позволяет прогнозировать вероятную успешность дальнейшего обучения; латентная валидность указывает на то, насколько тест соответствует определению уровней обученности; композиционная валидность заключается в оценке пригодности структуры теста для диагностики обученности; технологическая валидность оценивает уровень организации процесса тестирования (качество оформления, достаточность времени, отведенного на тестирование) [2].

Важным моментом при использовании тестовой технологии для организации самостоятельной работы, влияющим на ее качество, является содержание теста. Содержание теста определяется как оптимальное отображение содержания учебной дисциплины в системе тестовых заданий [1]. Содержание, которое отбирается для проверки, важность того или иного элемента содержания задается технологической матрицей [4]. Технологическая матрица может содержать уровни достижений, которые будут проверены, их соотношение, соответствие стандарту. Соотношение содержания стандарта и содержания теста является определяющим при создании теста, так как от достаточно точного и полного описания содержания стандарта и наиболее полного его выражения в тесте зависит диагностическая ценность тестовой технологии. 
В основу применения тестового контроля для организации самостоятельной работы студентов должна быть положена диагностическая система, представляющая собой упорядоченную совокупность взаимосвязанных элементов и включающая согласно классификации педагогического контроля, предварительный, текущий, тематический, рубежный, итоговый и заключительный этапы. В соответствии с этим различают педагогические тесты начального уровня обученности или входные тесты, тесты для текущего контроля, тематические тесты, рубежные, итоговые и заключительные, экзаменационные тесты, а также тесты остаточных знаний.

Входное тестирование - одна из форм осуществления преемственности между средней и высшей школой в процессе непрерывного образования. Она позволяет оценить уровень и структуру остаточных школьных знаний по предмету на момент организации самостоятельной работы и целенаправленно скорректировать учебный процесс, осуществить индивидуальный, дифференцированный подход к организации самостоятельной работы.

Применение тематического текущего и рубежного тестового контроля выступает как стимул регулярной самостоятельной работы студента в течение всего семестра, они используются для самоконтроля, так как позволяют своевременно реагировать на имеющиеся «пробелы» в знаниях. Между собой они различаются лишь объемом диагностируемого учебного материала.

Итоговые тесты, которые часто являются одновременно и экзаменационными, проводятся для оценки результатов обучения по окончании учебного курса.

Содержание итогового теста отражает содержание всего учебного курса, количественная доля заданий по отдельным темам курса определяется степенью их значимости на фоне учебного курса.

Тесты остаточных знаний отличаются от итоговых сроками проведения и ориентированы на выявление закрепившихся знаний по истечении некоторого срока после изучения учебной дисциплины.

Тестовый контроль, как средство установления прямой и обратной связи между преподавателем и студентами позволяет регулярно контролировать, своевременно корректировать и, таким образом, правильно организовывать и управлять самостоятельной работой студентов. Это свидетельствует о выполнении контролирующей, организующей, развивающей, ориентирующей, методической, воспитывающей, диагностической и прогностической функций тестового контроля [3, 11, 29].

Повышение результативности самостоятельной работы студентов в направлении контроля связано, прежде всего, с усилением текущего контроля за самостоятельной работой студентов в течение семестра, а также с усовершенствованием контрольных заданий.

В высших учебных заведениях России достаточно широко практикуется активизация систематической самостоятельной работы студентов в вузе с помощью специальных средств и методов контроля. Так в Брянском государственном техническом университете тестирование знаний студентов по иностранным языкам организуется в разнообразных формах. Прежде всего, тесты используются преподавателями при составлении учебных пособий. Данные тесты могут быть использованы как для контроля, так и для самоконтроля знаний студентов. Кроме того, возможности электронной образовательной среды вуза позволяют создавать и применять тестирование в дистанционном формате в реальном времени. Использование тестирования в данном формате позволило подготовить студентов, а затем и непосредственно провести викторину по страноведению дистанционно.

Достаточно большой мировой опыт научных и прикладных наработок в области педагогического тестирования показывает, что тестовый контроль органически вписывается в общую систему процесса обучения. Возможность использования тестов для контроля и самоконтроля свидетельствует о пользе их применения для контроля за результатами самостоятельной работы студентов.

$$
* * *
$$

1. Аванесов В.С. Композиция тестовых заданий: Учеб. кн. для преподавателей вузов, техникумов и училищ, учителей шк., гимназий и лицеев, для студентов и аспирантов пед. вузов / В.С. Аванесов. - [3. изд., доп.]. М.: Центр тестирования, 2002. - 238c. 
2. Веселкова Т.С. Междисциплинарные тесты как средство диагностики системности знаний учащихся (на примере школьного курса «Граждановедение»): Диссер. ... канд. пед. наук. Ижевск, 2000. - 148c.

3. Красноплахтова Л.И. Педагогическая техника преподавателя высшей школы как элемент педагогического мастерства: учеб. пособие / Л.И. Красноплахтова. - Краснодар: КубГАУ, 2015. - 97с.

4. Майоров А.Н. Отбор содержания образования для тестирования. Технологическая матрица // Школьные технологии. -1998. - №4. - С.205.

5. Профессиональная педагогика. / Под редакцией Батышева С.Я., А.М. Новикова. - 3-е изд., перераб. М.: Изво ЭГВЕС, 2009. - С.265.

6. Х Хуторской, А.В. Современная дидактика: учебник для вузов / А.В. Хуторской. — 3-е изд., перераб. и доп. Москва: Издательство Юрайт, 2021. - 406с.

\section{Червинская О.Ю., Балабаева В.В. \\ К вопросу становления и развития сети дошкольных учреждений города Севастополя} ФГАОУ ВО «Севастопольский государственный университет» «Гуманитарно педагогический институт»

(Россия, Севастополь)

doi: 10.18411/trnio-09-2021-64

\section{Аннотация}

В статье представлен краткий историко-педагогический обзор возникновения в Севастополе сети дошкольных учреждений; ее развитие в зависимости от общественнополитических и социально-экономических преобразований, от задач дошкольного образования на протяжении более ста лет (конец XIX века - начало XXI века).

Ключевые слова: сеть дошкольных учреждений, детский сад, детский очаг, ясли сад.

\section{Abstract}

The article presents a brief historical and pedagogical review of the emergence of a network of preschool institutions in Sevastopol; its development depending on socio-political and socioeconomic transformations, on the tasks of preschool education for more than a hundred years (the end of the XIX century-the beginning of the XXI century). garden.

Keywords: network of preschool institutions, kindergarten, children's hearth, nursery-

Пункт 3 статьи 18 Закона РФ «Об образовании» содержит термин «сеть дошкольных образовательных учреждений», которая действует для воспитания детей дошкольного возраста. В каждом регионе становление и развитие сети дошкольных учреждений имеет свои особенности.

Характерные особенности системы учреждений образования Севастополя в первую половину XX века наиболее полно изложены в учебных пособиях Е.Б. Алтабаевой. Но вопросы становления и развития сети дошкольных учреждений Севастополя еще не нашли полного изложения в историко-педагогической литературе. Исследование данной проблемы предполагает критическое осмыслений идей прошлого; содействует формированию представлений студентов о системе образования в регионе в процессе изучения дисциплины «История педагогики дошкольного образования».

Целью данной статьи является краткий историко-педагогический обзор изменения количества дошкольных учреждений Севастополя, их типологии от первых детских садов до современных дошкольных образовательных организаций.

Первые дошкольные учреждения в Севастополе появляются во второй половине XIX века. Т.М. Головань и Т.И. Пониманская, авторы монографии «Общественное дошкольное воспитание в Крыму», обосновали факторы, способствующие открытию дошкольных учреждений: рост занятости женщин в общественном производстве, увеличение количества 